\section{Water in the Gaza Strip}

alta III attendees unanimously adopted the following communiqué to be addressed to regional and world leaders. The document has been delivered to Tony Blair, envoy to the Middle East working on behalf of the United States, Russia, the United Nations, and the European Union.

\section{Resolution on Water in the Gaza Strip from the Conference on "Frontiers of Chemical Sciences III: Research and Education in the Middle East" (Malta-III)}

There are some concerns that transcend politics. Among them are issues that have long-term consequences for civilization and affect the lives of individuals who simply lie in the way of events.

Scientists from the Middle East and the rest of the world, including six Nobel laureates, gathered for the third conference in the series "Frontiers of Chemical Sciences: Research and Education in the Middle East." Among the most important issues discussed was the problem of water.

Water is of central importance to human life; water in the Gaza Strip is of particular concern in terms of quantity and quality, threatening the health of every inhabitant regardless of his or her political inclination.

The scientists at the meeting drafted a resolution in order to draw immediate and urgent attention to this issue. The resolution urges governments to look beyond the present conflicts and disagreements that afflict the region. As with some other treaties, where difficult conflicts are set aside for future consideration, the scientists urge all interested governments and agencies to ignore their current disagreements and, by drawing on scientific expertise, address the issue of water in the Gaza Strip, taking into account the whole cycle from collection to re-use.

This series of meetings continues to bring scientists from Middle Eastern countries and other nations together to discuss common problems and encourage collaborative research in the fields of energy, materials science, natural products, green chemistry, education, and the environment. A full report on the conference will be published in the May-June $2008 \mathrm{Cl}$.

Thill www.iupac.org/projects/2006/2006-035-1-020.htm

\section{Luis Oro to become EuCheMS}

\section{President}

rofessor Luis Oro, past president of the Real Sociedad Española de Quimica, has been elected as president elect of EuCheMS. He will become president in October 2008.

Prof. Oro has made important contributions to the renaissance of chemistry, not only in Spain, through his outstanding scientific contributions, but also through his selfless devotion to the championing and encouragement of chemistry at the European level. He has served as vice president of the European Science Foundation and as a member of the European Science and Technology Assembly, the CREST EU Committee, and the OECD Science Policy Committee. He is also the immediate past president of the Spanish Royal Society of Chemistry, having served as president from 2000 to 2005.

Prof. Oro is a professor of Inorganic Chemistry in Zaragoza and director of the Instituto Universitario de Catálisis Homogénea. His main research interests are in the coordination and organometallic chemistry of platinum group metals, where he has coauthored well over 500 scientific papers on synthesis, reaction mechanisms, and homogeneous catalysis. Professor Oro is a titular member of the IUPAC Inorganic Chemistry Division.

\section{iii. www.euchems.org}

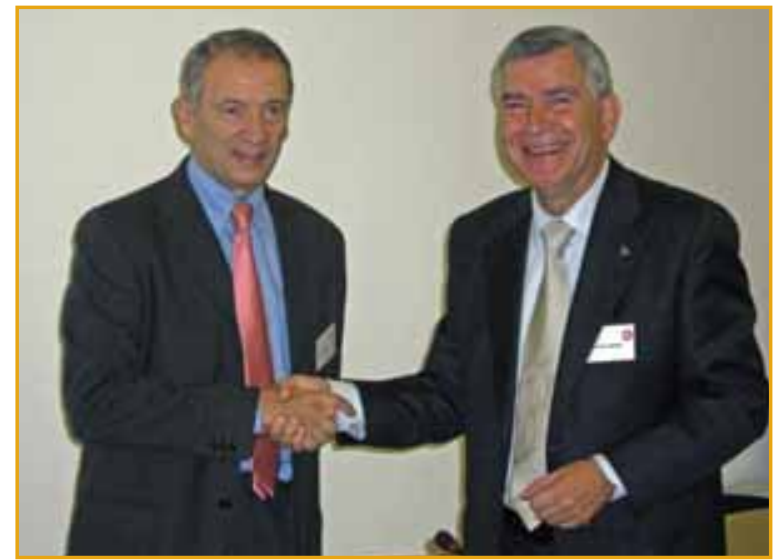

President Elect Luis Oro (left) is congratulated by Giovanni Natile, current president of EuCheMS. 